\title{
AI In Law Firms
}

\section{Gabriela Wiktorzak}

\section{Introduction}

Over the past five years, investment in the technology sector has increased significantly, and thanks to the diverse potential of artificial intelligence (AI) and blockchain, new means of solving current problems are emerging in a more efficient way. New sub-sectors of used technologies are also being created, such as: AgriTech, HealthTech, CleanTech, LegalTech, which, despite significant differences, have common features: they put the end user first, improve data flow and automate processes.

Innovations in law firms are not a new topic, as information technologies appeared in legal services much earlier. The 1970s are considered to be the beginning of the computer revolution in law firms, when Lexis-Nexis introduced UBIQ, a red computer terminal that allowed lawyers to search for case law in a database ${ }^{1}$. The revolution quickly progressed from document search to document creation, when Wang Laboratories introduced a computer with a new functionality - a word processor. The Wang systems entry into the market was a breakthrough for large law firms, because this new technology allowed them to store documents in a centralised manner and allow all their employees to edit texts ${ }^{2}$. Around the same time companies started buying fax machines too. In 1992, Microsoft Corporation released Version 3.1 of Windows ${ }^{3}$, which eventually replaced DOS, and Microsoft subsequent platforms successfully monopolized the PC market,

1 David Smetana, 'The Future of Legal Technology: 3 Emerging Trends' (5 August 2020) <https://www.chalkline.tech/blog/future-of-legal-technology-3-trends> accessed 30 September 2020.

2 See: Rob Hosier, 'Evolution of the Law Firm: Why Clients Demand that You Embrace New Technology' (Legal Futures, 28 October 2020) <www.legalfutures.co. uk/features/evolution-of-the-law-firm-why-clients-demand-that-you-embrace-new-te chnology>accessed 16 November 2020.

3 Maciej Gajewski, 'To były czasy. Kiedy po raz pierwszy uruchomiłem system z graficznym interfejsem i nie rozumiałem, co widzę ' (Spider's Web, 7 December 2018) <www.spidersweb.pl/2018/12/microsoft-windows-3-1.html> accessed 20 May 2020. 
causing a massive migration of law firms to Windows systems. Due to the growing demand, conditioned by the needs of customers and the changing market of services, lawyers had to tame and familiarise themselves with the Internet. Ignoring changing technological trends became impossible, even for such a conservative environment as lawyers, who were forced to make at least basic investments in the IT infrastructure of their law firms. Interest in innovation increased significantly, when LegalTech tools started to be enhanced with the AI element, even if all the confusion around AI sometimes seems to be based on an unrealistic vision of the possibilities of current technology ${ }^{4}$, a hypothetical machine that exhibits behaviour at least as skilful and sophisticated as the one of associated with a human. Nonetheless, today what is accessible to us is a "weak" or "narrow" AI that focuses on a single, specific task and can only be used in a limited context ${ }^{5}$.

However, regardless of its narrow scope, $\mathrm{AI}$ is transforming the way legal services are provided, predominantly in six main areas - litigation; automation of expertise; legal analysis; contract analysis; generating contractual and judicial documents; predictive analytics ${ }^{6}$. Artificial Intelligence in law firms today constitutes a digital system specifically designed for lawyers to help them do their job, and which integration has the potential to create a comprehensive solution for legal teams. Such tools were created in cooperation with lawyers who have the necessary knowledge that technology companies need to develop the most useful and optimal tools to provided services to their clients. Owing to machine learning, the system begins to make decisions with minimal programming. Instead of manually writing rules for a computer's interpretation of a dataset, machine learning algorithms (i.e. set of instructions which needs to be performed to solve a problem) allow the computer to specify the rules themselves. Such statistical techniques can be used for a wide range of activities - image analysis,

4 Andrew Ng, 'What Artificial Intelligence Can and Can't Do Right Now' (Harvard Business Review, 9 November 2016) <www.hbr.org/2016/11/what-artificial-intellig ence-can-and-cant-do-right-now $>$ accessed 21 November 2020.

5 Michael Bues, 'What AI in Law Can and Can't Do' (European Legal Tech Association) $<$ www.europe-legaltech.org/what-ai-in-law-can-and-cant-do/> accessed 2 February 2021.

6 Anthony E. Davis, 'The Future of Law Firms (and Lawyers) in the Age of Artificial Intelligence' (American Bar Association, 2 October 2020) <www.americanbar.org/groups/professional_responsibility/publications/professional_lawyer/27/1/the-future-law-firms-and-lawyers-the-ageartificial-intelligence/?q=\&wt=json\&start $=0>$ accessed 30 November 2020. 
fraud detection, price prediction and even $\mathrm{NLP}^{7}$, i.e. natural language processing technology. The next step in digital initiation is deep learning, which uses more advanced algorithms to perform more abstract tasks, such as image recognition ${ }^{8}$. Due to the fact that art of practicing law relies in large part on document analysis, the ability to read text using the right software, which at the same time gathers useful insights, is an advantageous attribute and the end result is impressive.

\section{Example:}

In a landmark study, which took place in Feburary $2018{ }^{9}$, American lawyers with years of experience in corporate law confronted the AI algorithm to detect problems in five non-disclosure agreements (NDA). After extensive testing, the AI accuracy rate averaged at 94\%, while lawyers achieved an average of $85 \%$. The lawyers' average time to complete the NDA analysis was 92 minutes. Artificial Intelligence only needed 26 seconds to do so. ${ }^{10}$

\section{AI i rozwój praktyki prawa}

Gottfried Wilhelm Leibniz, a famous lawyer, mathematician and 17th century polyhistor, once said: „It is unworthy of excellent men to lose hours like slaves in the labour of calculation which could safely be relegated to anyone else if machines were used. ${ }^{11}$ ". The dilemmas of the German philosopher were and are still current to the present day. Three hundred years later, we are once closer to answering Leibniz's questions.

7 See: 'Natural Language Processing vs. Machine Learning vs. Deep Learning' (24 June 2020) <sigmoidal.io/natural-language-processing-vs-machine-learning-vs-dee p-learning/> accessed 15 December 2020.

8 Khalid Al-Kofahi, 'Cognitive Computing: Transforming Knowledge Work, Transforming Knowledge Work' (27 January 2017) <www.blogs.thomsonreuters.com /answerson/cognitive-computing-transforming-knowledge-work/> accessed 15 December 2020.

9 See: 'Comparing the Performance of Artificial Intelligence to Human Lawyers in the Review of Standard Business Contracts' (Law Geex Paper 2018) <www.images .law.com/contrib/content/uploads/documents/397/5408/lawgeex.pdf $>$ accessed 30 November 2020.

10 ibid.

11 See biographical note: <www.math.dartmouth.edu/ $\sim \mathrm{m} 3 \operatorname{cod} /$ LeibnizWheelBig.ht $\mathrm{m}>$ accessed 30 September 2020. 
There are many solutions available on the market, created for individual, small and medium-sized law firms respectively, the functionalities of which can be adapted to clearly defined needs of users. A client can choose the right software solution, which fits one's needs (desktop application, client-server application or web application $)^{12}$. Over the past few years, more and more organizations have started to abandon on-premises serverbased software for cloud-hosted services. Despite the risks associated with such a change, law firms, as well as the in-house legal teams through such a transformation, have the opportunity to benefit from seamless remote access, availability assurance and significant long-term cost savings. The cloud has popularized Software as a Service (SaaS) solutions, and many law firm management tools are delivered using software-as-a-service model, where a manufacturer provides both the operating system, server space, and the application. Regardless of the software model chosen, law firm management systems have basic functions such as document management, customer relationship management (CRM), ability to build case management procedures and work cycle, synchronization with an e-mail inbox. With the available applications, you can create electronic files, and in them a case plan - templates, dedicated to the relevant legal proceedings, which automatically set all tasks, questions, deadlines and actions that will take place during the conduct of the case or litigation.

A practical complement to such a system is the document management function (DMS), which allows you to model a number of different processes for the purpose of document circulation. Back in 2018, a significant trend in document management software was to ensure increased document functionality. Therefore, companies that created such solutions, rather than just allowing online storage and document organization, have begun adding additional features to their products that allow users to create, annotate, and collaborate on legal documents. For example, document collaboration and sharing features are available on some platforms, which greatly facilitates secure collaboration on documents with customers, colleagues, experts. Another feature included in some software products is the conversion of scanned documents to an optical character recognition

12 Majchrzak and Sowiński, <https://www.oirpwarszawa.pl/wp-content/uploads/202 0/10/programy-do-zarzadzania-kancelaria-prawna--jak-wybrac-i-wdrozyc-najlepszy -program-dla-twojej-kancelarii.pdf> accessed 30 November 2020. 
format that creates searchable, indexed PDFs. Other useful features include annotation tools, electronic signatures, and customized security features ${ }^{13}$.

\section{AI for legal in-house teams and law firms}

John Grisham, an American bestselling author and lawyer by profession, stated in his first book Time to Kill, that what a good lawyer is worth if he can't find an important document in thirty seconds ${ }^{14}$. The fictional characters in Grisham's novel were aware of the important aspect of access to information, analysis of documents and their proper organization, which indissolubly embedded within the reality of this profession. In the work of a lawyer, the provision of objective advice is their bread and butter, and the final results they deliver must be based on detailed and reliable data. AI tools can support the legal departments and law firms by offering the insightful and fast analysis that demanding customers need.

Today, the most prevalent AI are those legal technologies that deal with repetitive work and manage large amounts of documents more effectively, while minimizing the risk of legal errors. ${ }^{15}$ Some of these technologies will be analysed below.

\subsection{Document analysis - Document Review and E-discovery}

Many legal tasks require the knowledge of lawyers and a thorough understanding of the various legal documents. It takes a long time to find and understand the collection of gathered evidence, even for lawyers. ${ }^{16}$ Software that uses NLP can be deployed to read legal documents and to extract useful information, often at the clause level or when key data is

13 Nicole Black, 'The Latest on Legal Document Management Software' (ABA Journal, 27 April 2020) <www.abajournal.com/web/article/the-latest-on-legal-docume nt-management-software> accessed 29 May 2020.

14 John Grisham, A Time to Kill (Delta 2004) 369.

15 Rasminna Roslin, 'Legal Technology and In-house Counsels Today' (Staranise, 1 June 2020) <www.staranise.com.hk/knowledge-hub/articles/legal-technology-in-h ouse-counsels.html> accessed 30 September 2020.

16 Haoxi Zhong, Chaojun Xiao, Cunchao and others, 'How Does NLP Benefit Legal System: A Summary of Legal Artificial Intelligence' (Proceedings of the 58th Annual Meeting of the Association for Computational Linguistics,on-line, July 2020) 5218-5230<www.aclweb.org/anthology/2020.acl-main.466.pdf $>$ accessed 1 July 2020. 
stored within clauses. This technology presents an expedient way to deal with due diligence in mergers and acquisitions and is valuable in terms of extracting leasing data for large-scale real estate transactions.

E-discovery is the process of obtaining and exchanging evidence or electronically stored information (ESI) that could potentially become evidence in litigation. The first stage of E-discovery is the collection of data that can be used in legal proceedings or investigations. In addition, forensic IT programs ${ }^{17}$, enable organizations to accurately collect and preserve potentially relevant (responsive) data, both on-premises and in cloud. The parties to the proceedings often disagree as to which method of identifying potentially responsive electronically stored information is best. In particular, the method of using keywords compared to Technology Assisted Review (TAR) is usually a topic of long debates ${ }^{18}$. Technology Assisted Review is a method, which can be deployed during the document review phase that uses algorithms to identify and mark potentially responsive documents based on keywords and other metadata. The advantage of TAR is that it can help significantly accelerate the document review process. ${ }^{19}$ During a disclosure process, when evidence is shared with the requesting party, such documented evidence is converted to a different format, such as TIFF or PDF, which allows the editing and redacting of privileged and irrelevant information. ${ }^{20}$ Using TAR (or computer assisted review, CAR), predictive encoding in combination with analytics software for E-discovery, reduces the number of documents required for review and allows the legal team to prioritize the analysis accordingly. Narrowing the scope of documentary review in such a way, reduces hours and thus costs. The ultimate purpose of E-discovery is to provide the essential amount of evidence for litigation in a defensive manner.

The future of E-discovery with the capabilities of TAR seems quite revolutionary thanks to so-called legal ontology, which represent a new structure for aggregating and organizing information in such a way that it

17 Russell Chozick, 'The Major Differences Between Digital Forensics and E-discovery' (Flashback Data, 30 June 2017) <www.flashbackdata.com/digital-forensics-vsediscovery/> accessed 20 January 2021.

18 Kathryn Cole, 'Judges Make the Case for TAR' (Farrell Fritz, 17 February 2021) $<$ www.allaboutediscovery.com/2021/02/judges-make-the-case-for-tar/> accessed 24 February 2021.

19 See: 'What Is Technology-Assisted Review or TAR?' <www.zapproved.com/blog/w hat-is-technology-assisted-review-tar/> accessed 24 February 2021.

20 Kathryn Cole, 'In What Format Should I Make My Production? And, Does Format Matter?’ (JD Supra, 3 June 2019) <www.jdsupra.com/legalnews/in-what-format-should-i-make-my-61643/> accessed 24 February 2021. 
can be understood and processed by machines. Their principal advantage is that they consist of concepts, relations, instances, and axioms, as opposed to ordinary keywords. This allows professionals to streamline their work by looking for legal concepts or precedents instead of just keywords ${ }^{21}$.

\subsection{Contract review/management software}

Lawyers are often involved in contract negotiations, and their role is to advise whether the proposed contract reflects the client's intentions and expectations, or whether it requires appropriate changes, improved terms and conditions. Some agreements can be relatively simple, e.g. previously mentioned non-disclosure agreements (NDA), in contrast to very complex contracts that often extend over hundreds of pages. Automated contract analysis systems can be used to review documents that are relatively standardized and predictable in terms of the type of content they contain ${ }^{22}$. This process involves dividing the contract into individual terms or clauses, and then evaluating each of these elements, in order to extract key information or compare it with a certain standard, which is based on the information collected and examples of contracts contained in the company's database. Such a structured contract review system may indicate which provisions are missing from the contract and which are relevant to the customer, or indicate that the clauses covering the change in the rates in force during the term of the contract do not set a cap on the percentage increase in charges. It can then provide an example wording as an alternative based on how such a clause is usually formulated, according to company standards.

The contract automation described above is only one aspect of the wide range of functionalities offered by available contract lifecycle management AI platforms, because modern contract management systems are able to support the entire process, from contract creation, through negotiation and review of terms, electronic signatures, to monitoring the performance

21 Harry F. Karoussos, 'Law \& The Digital Disruption: The Impact of ICT and AI on the Legal Profession' (2017) American College of Greece Research Paper $<$ www.researchgate.net/publication/321527178_Law_The_Digital_Disruption_Th e_Impact_of_ICT_and_AI_on_the_Legal_Profession> accessed 25 February 2021.

22 Robert Dale, 'Law and Word Order: NLP in Legal Tech' (Towards Data Science, 15 December 2018) <www.towardsdatascience.com/law-and-word-order-nlp-in-legal -tech-bd14257ebd06> accessed 4 January 2020. 
of contractual obligations of the parties to the contract and analysis of the commercial relationship ${ }^{23}$. In 2020, there was a clear trend in contract management software on the market. It transpired that everyone is observing and looking for ways how to exploit and use data to generate immediate value, and how to prepare for a future, where AI is likely to replace today's simple automation. While basic features such as electronic signature have become a necessity, current trends favour advanced systems that support the entire contract lifecycle management ${ }^{24}$.

\subsection{Legal information systems and predictive analytics}

Based on the UBIQ concept, many similar databases for court decisions and legal acts have been created, without which most modern lawyers cannot imagine functioning in their profession. The applications that are currently available on the market are an improved version of legal research software, enriched today with NLP. This natural language processing addon enables more complex and improved searches, allowing you to identify entire segments of text, not just keywords. This extended approach to creating more effective tools for lawyer work is based on the assumption that a given problem, which becomes the subject of legal analysis, is more easily solved using different techniques (such as indexes and legal commentary table of contents), as opposed to clearly defined phrases for which search algorithms are used. ${ }^{25}$ It has become obvious that the quality of search results depends significantly on the right queries raised. Therefore, many of the solutions currently available on the market provide interfaces that allow you to find related materials by uploading a fragment or even the entire text that provides the search context, and as a result supporting "query by document". Apart from reducing the time spent on sufficiently detailed

23 Mikkel Boris, 'Top Trends in Contract Management 2020' (Contractbook, 31 August 2020) <www.contractbook.com/legaltechinstitute/top-trends-in-contract -management-2020> accessed 3 September 2020.

24 ibid.

25 Paul Callister, 'Law, Artificial Intelligence, and Natural Language Processing: A Funny Thing Happened on the Way to My Search Results' (2020) 112 Law Library Journal 161-212 <www.papers.ssrn.com/sol3/papers.cfm?abstract_id=3712 306> accessed 24 February 2021. 
search queries, the likelihood of finding additional relevant material that would not be found using typical queries has also increased ${ }^{26}$.

As part of going a step further, some legal information systems have an additional predictive analytics function that uses some form of NLP and machine learning to ensure enhanced searching and better understanding of legal issues, especially case law and legal precedents. This specific realm also includes systems for analysing behaviour for the purposes of litigation, such as anticipating the behaviour of judges and jury ${ }^{27}$. These systems have been trained to detect certain types of language, and by analysing historical data, the user receives a statistical assessment of whether the judge will respond and rule in the same way to a new but similar case.

\section{Compliance. Risk management}

One of the reasons for the global financial crisis of 2007-2008 was the mismanagement of risk data and the unawareness of regulators about the accumulated systemic risks arising from contractual obligations. To avoid repeating the same mistakes, today's institutions need to be active in data management, on compliance ${ }^{28}$, and they are supported by appropriate innovative solutions that assist them with apprehending and facilitating advanced risk management in a given sector of the economy. These systems use NLP, among other things, to verify that the contracts concluded by a company comply with the laws and policies of the organization. Such technology has gained great popularity with regard to the GDPR. Artificial intelligence for compliance consists primarily of rigidly coded legal knowledge and rules, and when the law cannot be encoded, with alerting mechanisms. As a result, some notification and alert techniques may help an organization with meeting its relevant legal requirements ${ }^{29}$.

26 Robert Dale, 'Law and Word Order: NLP in Legal Tech'(2019) 25(1) Natural Language Engineering .

27 See: 'Legal Research + Analytics' (Artificial Lawyer) <www.artificiallawyer.com/al -100-directory/legal-research-analytics/> accessed 24 February 2021.

28 See: 'LegalTech + RegTech = Tools for an Increasingly Complex World' (Planet Compliance $<$ www.planetcompliance.com/legaltech-regtech-tools-for-an-increasin gly-complex-world/> accessed 23 January 2021.

29 Marcelo Corrales, Paulius Jurčys, George Kousiouris, 'Smart Contracts and Smart Disclosure: Coding a GDPR Compliance Framework' (2018) SSRN Electronic Journal <www.researchgate.net/publication/323625892_Smart_Contracts_and _Smart_Disclosure_Coding_a_GDPR_Compliance_Framework $>$ accessed 30 November 2020. 
This is done by training algorithms accordingly, by marking each alert as a "true negative" or as a "false positive" 30 . The system will continue to identify patterns while receiving an opinion on the AI model and thus learn through decision-making experience, on the basis of statistical data, what should be notified to the organisation. Improved AI models will allow lawyers to focus on investigative work to understand the context of potentially risky employee activity.

\section{Summary}

The pace of the technological revolution in law firms is relatively slow, which is mainly due to the accepted model of fee earning, based on the hours worked - any increase in productivity offered by AI tools means less remuneration for lawyers. Moreover, the available budget has always been the prevalent barrier to technological innovation, and the skills gap continues to effectively halt a possible change. Artificial Intelligence, for the in-house teams too, is slowly evolving and legal departments seem to be lagging behind other functions in the use of new technologies. Nevertheless, there are many factors that affect not only attitudes but also the transformation of companies in the market. More and more companies are choosing to hire in-house lawyers, who constantly create new model contract templates, and update and introduce new procedures, as well as internal policies. For them, completing projects as soon as possible is crucial to be able to focus on the tasks they perform on a daily basis and to meet the requirements of their employer. Another circumstance that motivated the market to reflect at least on the current model of service provision was the COVID-19 virus pandemic. Coronavirus, which spread around the world in 2020, has forced many organisations to revise their plans, strategies, targets, and re-examine risk management processes and their approach to growth and technological transformation ${ }^{31}$. While until recently in-house legal teams were not considered to be leaders in modernization and automation, the pandemic reduced staff budgets and at the

30 Jordan Domash, 'AI and its Impact on the Future of Regulatory Compliance' (A-Team Insight, 9 September 2020) <www.a-teaminsight.com/ai-and-its-impact-on -the-future-of-regulatory-compliance/?brand=ati> accessed 30 September 2020.

31 See: 'Looking Glass Report. The Role of the General Counsel in Navigating the Global Risk Landscape' (Clyde\&Co) <www.clydeco.com/en/looking-glass-report> accessed 3 December 2020. 
same time increased the legal burden; new technologies have become the most obvious solution for many legal departments ${ }^{32}$.

The reality seems to be conducive to the implementation and further improvement of AI products available on the market, which was worth $\$ 17.32$ billion in $2019^{33}$. However, perhaps due to the number of options available, small and medium-sized law firms as well as in-house lawyers often find it difficult to identify the most practical technology from their perspective. Technology that can be effectively implemented in your organization while changing the way you provide services to improve efficiency and manage your customers more efficiently. As soon as the identified objectives can be achieved, managing the ever-increasing pressures of today's business environment can be much painless and result in the possibility of using increased data not only to streamline internal processes, but also to better understand trends and make decisions based on reliable information. Change is inevitable, transformational technologies will become more important as customers want to spend less and work more on their own ${ }^{34}$.

According to the "Future Ready Lawyer" study ${ }^{35}$ law firms are undergoing a significant transformation, especially in the context of how services are provided, and the biggest changes that can be expected in the near future are primarily:

1) wider use of technology to improve efficiency;

2) greater specialisation of services;

3) focus on innovation.

32 Rob Van der Meulen, '5 Legal Technology Trends Changing In-House Legal Departments' (Gartner, 9 February 2021) <www.gartner.com/smarterwithgartner/5legal-technology-trends-changing-in-house-legal-departments/> accessed 24 February 2021.

33 Thomas Alsop, 'Legal Tech Market Revenue Worldwide from 2019 to 2025, by Business Type' (Statista, 26 January 2021) <www.statista.com/statistics/1168096/le gal-tech-market-revenue-by-business-type-worldwide/> accessed 30 January 2021.

34 See: Report: 'Future Ready Lawyer. Czynniki efektywności' ('Future Ready Lawyer. The Efficiency Factors') Wolters Kluwer $2020<$ www.lrpoland.wolterskluwer.com /Future-Ready-Lawyer-2020?utm_source=mail_klienci\&utm_medium=organic\& utm_campaign=WKPL_LEG_ACQ_LEX-EBO-FRL2020-06-20-TOFU_LFM/PRW 0520014_CIN002\&utm_term $=$ mai_klienci\&utm_content $=$ klienci $>$ accessed 15 February 2021.

35 ibid. 
Gartner $^{36}$, on the other hand, lists five LegalTech trends that will shape in-house legal departments over the next few years::

1) the spend on legal technology will increase threefold;

2) $20 \%$ of generalist lawyers will be replaced with nonlawyer staff, who have other skills or experience than those, which are normally developed by lawyers;

3) automating $50 \%$ of legal work related to major corporate transactions;

4) only $30 \%$ of the potential benefit of their contract life cycle management investments will be captured by corporate legal departments.

5 ) at least $25 \%$ of spending on corporate legal applications will go to nonspecialist technology providers.

There are also opinions that soon the element of the lawyer's intellectual work will disappear ${ }^{37}$, however, the vast majority of experts consider that the impact of AI on activities such as drafting opinions, advising clients or representing them will not be significant ${ }^{38}$. AI is supposed to unleash the potential of a lawyer, who is looking for a place in a competitive market, giving him/her the opportunity to focus on what he or she does best by giving clients bespoke advice and handling non-standard aspects of transactions.

36 Rob Van der Meulen, '5 Legal Technology Trends Changing In-House Legal Departments'.

37 See: 'Digital Transformation: Assessing the Impact of Digitalisation on Ireland's Workforce' (2018) Expert Group on Future Skills Needs Report <www.skillsireland.ie/all-publications/2018/digital-transformation-assessingthe-impact-of-digitalisation-on-ireland-s-workforce.html > accessed 7 August 2020.

38 Rónán Kennedy, 'Algorithms, Big Data and Artificial Intelligence in the Irish Legal Services Market' Oireachtas Library \& Research Service, $2021<$ www.data.oi reachtas.ie/ie/oireachtas/libraryResearch/2021/2021-02-18_spotlight-algorithms-bi g-data-and-artificial-intelligence-in-the-irish-legal-services-market_en.pdf $>$ accessed 24 February 2021. 
Figure 14. The process of determining specification requirements and frequently encountered difficulties
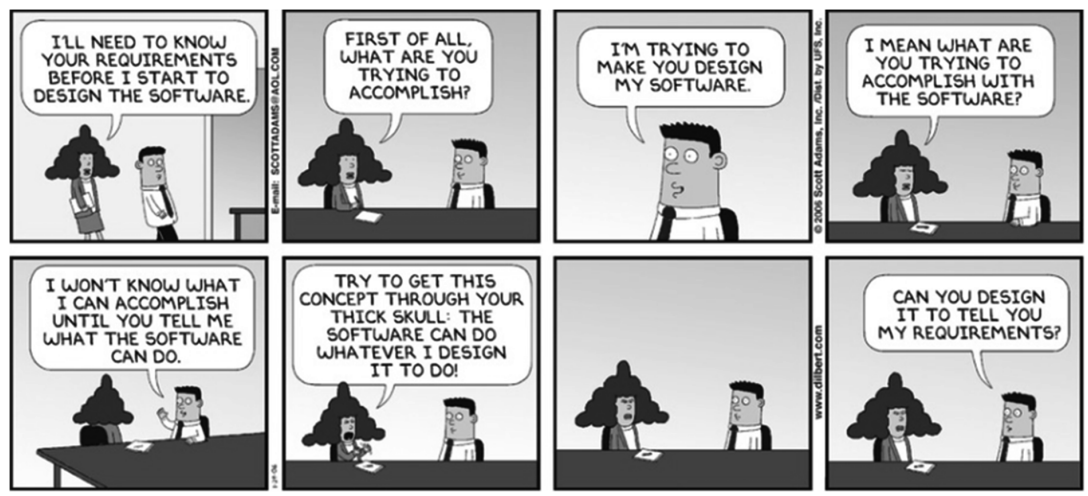

Source: Dilbert by Scottt Adams, 29 January $2006<$ www.dilbert.com/strip/2006-01 -29> accessed 24 February 2021

While it is important to know the tools that are currently available, the priority for each organisation should be primarily to be aware of its position in the market and the role it plays or wants to play. It is of utmost importance to understand the data that a law firm or in-house legal department produces. The information contained in structured data sets can have an immeasurable impact not only on the quality of the services provided, but also on the efficiency of their implementation. Any implementation of the new system should be pre-planned with focusing on a careful analysis of existing processes and circumscribing essential needs. A detailed analysis of the legal aspects of AI will become paramount in order to develop an analytical framework that can serve as a checklist of identified legal areas to be taken into account for individual AI projects ${ }^{39}$. In an era of zetabytes and the likelihood of more pandemics, agile management skills and the ability to adapt quickly are crucial for any business, including lawyers.

39 See: Chris Kemp, 'Legal Aspects of Artificial Intelligence (v.3.0)', (2021) Kemp IT Law White Paper <www.kempitlaw.com/legal-aspects-of-artificial-intelligence-v3 -0/> accessed 24 February 2021. 
